\title{
Tecnologias digitais e formação continuada de professores
}

\author{
Technologies in school and continuing teacher education \\ Las tecnologías digitales y la formación continua de los docentes
}

\author{
RICARDO ANTUNES DE SÁ* \\ ESTELA ENDLISH**
}

\begin{abstract}
RESUMO - Apresenta-se a sistematização de resultados preliminares de pesquisa empreendida junto às escolas da Rede Municipal de Educação de Curitiba - RME, onde se investigaram os conhecimentos adquiridos pelos professores nos cursos de formação continuada e a integração dos recursos das tecnologias digitais na escola no período de 2011 a 2012. O quadro teórico utilizado foi: André (2013), Lüdke e André (1986), Castells (2003), Kenski (2007, 2010, 2013), Lemos e Lévy (2012), Marcelo (2009), Moran (2002, 2011), Sancho (2002), Santaella (2003, 2007), Recuero (2012). Os resultados apontaram para a necessidade de uma concepção de formação continuada que propicie elementos teóricos e metodológicos que fundamentem a integração crítica e propositiva dos recursos tecnológicos digitais à prática educativa. É preciso avançar no sentido de tecer um diálogo mais efetivo entre o conteúdo, o conhecimento, a episteme e os meios (e suas linguagens) veiculados pelas tecnologias digitais.

Palavras-chave - Educação. Tecnologia na escola. Formação continuada de professores.
\end{abstract}

\begin{abstract}
Presents the preliminary results of systematic research undertaken in the schools of the Municipal Education Network Curitiba - RME, where we investigated on the knowledge acquired by teachers in continuing education courses and resources integration of digital technologies in school in from 2011 to 2012. The theoretical framework used was: André (2013), Lüdke and André (1986), Castells (2003), Kenski (2007, 2010, 2013), Lemos and Lévy (2012), Marcelo (2009), Moran (2002, 2011) Sancho (2002),Santaella (2003, 2007), Recuero (2012). The results indicated the need for a concept of continuing education that fosters theoretical and methodological elements that support the critical and purposeful integration of digital technology resources for educational practice. We must move towards a more effective dialogue weave between content knowledge, episteme and the means (and their languages) conveyed by digital technologies.

Keywords - Education. Technology school. Continuing teacher education.

RESUMEN - Presenta los resultados preliminares de la investigación sistemática realizadas en las escuelas de la Red de Educación Municipal de Curitiba - RME, donde se investigó en los conocimientos adquiridos por los profesores en cursos de educación continua y la integración de los recursos de las tecnologías digitales en la escuela en 2011-2012. El marco teórico utilizado fue: André (2013), Lüdke y André (1986), Castells (2003), Kenski (2007, 2010, 2013), Lemos y Lévy (2012), Marcelo (2009), Moran (2002, 2011), Sancho (2002), Santaella (2003, 2007), Recuero (2012). Los resultados indicaron la necesidad de un concepto de educación continua que fomenta elementos teóricos y metodológicos que apoyan la integración crítica y propositiva de los recursos de tecnología digital para la práctica educativa. Debemos avanzar hacia un tejido diálogo más eficaz entre el conocimiento del contenido, episteme y los medios (y sus lenguas) ser entregados por las tecnologías digitales.
\end{abstract}

Palabras clave - Tecnología de la educación en la escuela. Formación continua de los docentes.

\footnotetext{
* Doutor em Educação pela Universidade Estadual de Campinas (Campinas, SP, Brasil) e Professor na Universidade Federal do Paraná (Curitiba, PR, Brasil). E-mail:<antunesdesa@gmail.com>.

**Gerente de Tecnologias da Secretária Municipal Educação de Curitiba (Curitiba, PR, Brasil). E-mail: <endlich@sme.curitiba.pr.gov.br>.
} 


\section{INTRODUÇÃO}

A mudança do panorama contextual, do ponto de vista da evolução científica e tecnológica, tem colocado à instituição escolar e a seus profissionais professores novas incumbências e desafios relativos à aprendizagem, à docência e ao conhecimento (ASSMANN, 2005; KENSKY, 2013). Trata-se de uma tomada de posição quanto ao projeto formador da escola no sentido de redimensioná-lo em relação às possibilidades de novas mediações pedagógicas entre estudantes, professores e os processos culturais (digitais) da sociedade. A função social da escola não se discute; contudo, observa-se que hodiernamente diversificam-se as formas de interação social (RECUERO, 2012; SILVA, 2012), as quais indicam a necessidade de uma reconfiguração das práticas docentes associadas à integração das tecnologias digitais.

A proposta do presente artigo é descrever e analisar pesquisa desenvolvida em 2012, intitulada: "Formação continuada de professores para a integração dos recursos tecnológicos nas escolas da Rede Municipal de Ensino de Curitiba" (que é um desdobramento da pesquisa "Professores, tecnologia e escola: formação e prática escola"), que investigou proposta de formação continuada de professores, a integração dos recursos das tecnologias digitais e seus reflexos na prática docente e na escola.

A pesquisa qualitativa de cunho exploratório (ANDRÉ, 2013; LÜDKE; ANDRÉ, 1986) foi realizada a partir da aplicação de questionários junto aos professores que participaram dos processos da formação continuada no período de 2011 a 2012.

A proposta de formação em serviço pretendeu estabelecer uma articulação entre os conteúdos curriculares e os recursos tecnológicos disponíveis nas escolas. A iniciativa de formação continuada constituiu uma experiência de formação que procurou estabelecer um "diálogo" entre os conhecimentos das áreas trabalhadas na escola de Ensino Fundamental com as possibilidades de integração dos recursos tecnológicos em sala de aula. Os resultados apontaram para algumas possíveis ações que podem contribuir para o avanço da apropriação e integração das tecnologias da informação e da comunicação à prática pedagógica dos professores da Rede Municipal de Ensino de Curitiba.

\section{HISTÓRICO DO USO PEDAGógICO DOS COMPUTADORES NA SME}

Segundo as Diretrizes Curriculares para a Educação Municipal de Curitiba (CURITIBA, 2006), as primeiras experiências para o uso pedagógico dos computadores na RME datam de 1992 em duas escolas e, em 1994, amplia-se para mais três escolas. Em 1997, elabora- se uma política institucional para instalação gradativa de laboratórios de informática, aquisição de softwares educacionais e capacitação para as 150 escolas municipais existentes na época.

Em 1998, cinco empresas do ramo viabilizam os custos de "escolas-vitrinas" em cinco unidades escolares com a finalidade de que as outras escolas pudessem observar, discutir, questionar e selecionar a proposta que mais se adequasse à sua concepção de tecnologia educacional (SANCHO, 2002). A partir de 1999, todas as escolas implantam, de maneira gradativa, laboratórios de informática.

Para atender às demandas pedagógicas desse processo, em 2001 é criado o setor de Tecnologias Educacionais, para acompanhamento e implementação de novos ambientes de aprendizagem digital e que se mantém até os dias atuais no Departamento de Tecnologias e Difusão Educacional.

No período de 2001 a 2005, foram ofertados cursos que previam a utilização de ferramentas como sites, softwares e kits de construção mecanizados, dentre eles o de robótica, prevendo a aplicação prática dos conhecimentos adquiridos, a qual era convertida em carga horária, valorizando também a aplicação dos conteúdos aprendidos em atividades realizadas com os estudantes.

No ano de 2005, teve início o projeto Cri@tividade com o objetivo de verificar cientificamente como se dava a integração das TICs no planejamento do professor. O projeto apostava na figura do professor-mentor, que era um docente da própria escola com habilidade pedagógica para o uso de tecnologias no processo educativo. Este profissional havia recebido formação especializada com acompanhamento da Gerência de Tecnologias Digitais ao longo do ano letivo e tinha como principal função articular os conteúdos curriculares com as ferramentas digitais, bem como assessorar os demais professores da unidade, auxiliando-os, no cotidiano da escola, a superarem sua insegurança e falta de conhecimentos "tecnológicos".

A partir do ano de 2009 e até 2012, percebeu-se a necessidade de avançar na formação dos professores integrando as ferramentas digitais, não em cursos específicos de tecnologias educacionais e sim inserindo a tecnologia nos cursos que tratavam especificamente das áreas do conhecimento. A pesquisa desenvolvida e apresentada neste artigo, portanto, procura analisar esta tentativa de integração das áreas do conhecimento com os recursos tecnológicos.

O conhecimento técnico é necessário, mas não suficiente para dar conta da dimensão pedagógica; por outro lado, o uso pedagógico necessita de conhecimentos tecnológicos para se integrar no planejamento didáticopedagógico e na utilização crítica e criativa das tecnologias na escola. Na década de noventa do século 
passado, Valente já dizia em relação à integração da informática na escola que "os grandes desafios dessa área estão na combinação do técnico com o pedagógico e, essencialmente, na formação do professor" (1999, p. 23).

\section{TECNOLOGIAS NA CONTEMPORANEIDADE}

A tecnologia sempre se constituiu ao longo da história da humanidade numa forma de o homem poder interferir na natureza, modificá-la, alterá-la de tal forma que pudesse garantir sua sobrevivência material e espiritual. A tecnologia revela o grau de complexidade que determinada civilização ou sociedade atingiu num determinado tempo histórico (KENSKI, 2013; LEMOS; LÉVY, 2010).

Em conformidade com as reflexões de Lyotard (1988, 1993) um dos grandes desafios para o homem é saber ou aprender a acompanhar o movimento, as transformações pelas quais passa o mundo e aprender a lidar com essa complexidade que a tecnologia impõem a todos. Com isso, há um grande desafio para a escola, para a universidade e para os professores, no sentido de uma apropriação e compreensão crítica da dialogia que existe intrinsecamente à tecnologia referente a duas dimensões: emancipadora e/ou alienadora.

A tecnologia se constitui num processo de desenvolvimento da ciência e da técnica que articulam um conhecimento historicamente produzido e complexificado que resultaram, nos tempos atuais, na revolução tecnológica digital, no surgimento do computador, nas possibilidades infindáveis de comunicação síncrona e assíncrona; numa disponibilização de informação nunca antes vista na história da humanidade; nos processos multidirecionais de comunicação, tornando o receptor tão ativo quanto o emissor e tão influente sobre a informação quanto este (SANTAELLA, 2003).

A criação da rede mundial de computadores (internet) vem possibilitando o surgimento e desenvolvimento das redes sociais (RECUERO, 2012) virtuais. Tudo isso num tempo histórico relativamente pequeno e que vem influenciando os diversos setores da sociedade em geral e em particular a escola. Segundo Castells (1999, 2003), é preciso analisar as transformações das culturas humanas à luz dos novos sistemas eletrônicos de comunicação, porque está surgindo uma cultura da virtualidade real. De acordo com Schwartz (2005, p.5), há que se considerar os indicativos de evolução referentes à convergência digital entre telefonia, internet e telecomunicações, que, além de modificar as redes de conexão entre infraestruturas nos diversos setores econômicos e sociais, modificam os comportamentos e as relações humanas e institucionais. $\mathrm{O}$ autor ainda afirma que "mais do que à informação, é ao processo de produção de conhecimento e conteúdo que remetem cada vez mais as estruturas tecnológicas digitais e interativas".

O atual contexto social de uso das Tecnologias da Informação e da Comunicação (TIC), especialmente na configuração de espaços virtuais (ciberespaço), apresenta contornos específicos na formação de hábitos e atitudes, ou seja, está-se diante da complexidade do ciberespaço (LEMOS; LÉVY, 2010) em que os fundamentos da comunicação e da aprendizagem se configuram de maneira diferente daquela que tradicionalmente os cidadãos estão acostumados.

Em relação à escola, as TICs representam, de certa forma, uma revolução nos processos lineares e tradicionais de comunicação escolar, uma cultura baseada na oralidade, na escrita linear, na leitura linear, com pouca apropriação das novas linguagens manifestadas nas tecnologias contemporâneas que invadem o espaço educativo escolar. As TICs precisam ser concebidas em suas especificidades, características e linguagens, as quais se tornam, no âmbito do processo educativo, mediadoras entre os atores do processo pedagógico (professores e alunos). O foco do processo passa a ser a própria aprendizagem nas interações multidirecionais, não lineares. Conforme Moraes (2004, p. 258): "Somos produtores e, ao mesmo tempo, produtos das experiências que vivenciamos. Essas experiências, por sua vez, passam a apresentar uma característica auto formadora importante nos processos de aprendizagem [...]".

\section{ESCOLA, TECNOLOGIAS E FORMAÇÃO CONTINUADA}

A escola na contemporaneidade é instada a desenvolver seu histórico papel de formação das novas gerações, articulando-se de alguma forma com as novas formas de produção e distribuição da informação e do conhecimento. Deixou de ser a instituição hegemônica que detém o conhecimento, o monopólio do saber. As tecnologias da informação e da comunicação desenvolvidas na era da tecnologia digital têm criado novas formas de acesso, distribuição e manipulação do conhecimento (ASSMANN, 2005; SANTAELLA, 2003; RECUERO, 2012) num mundo globalizado (IANNI, 1993, 1997).Nesse sentido, para ser professor no século XXI, é preciso:

[...] assumir que o conhecimento e os alunos [...] se transformam a uma velocidade maior à que estávamos habituados e que, para se continuar adar resposta adequada ao direito de aprender dos alunos, teremos de fazer um esforço redobrado para continuar a aprender (MARCELO, 2009, p. 8). 
A formação continuada, então, reveste-se de uma permanente necessidade para o desenvolvimento profissional docente e, no caso das tecnologias, é preciso que se instale um processo de diálogo crítico e reflexivo sobre os fundamentos teóricos e metodológicos do uso dos recursos tecnológicos na escola. Educar com novas tecnologias é um grande desafio que precisa ser enfrentado (MORAN, 2002).

A par disso, é necessário ter clareza de que a tecnologia é um meio para efetivar a formação humana na escola. A tecnologia não pode ser tomada em si ou por si só, mas sempre pensada e praticada dentro de um contexto, percebida e utilizada como um meio para potencializar e qualificar os processos formativos e educativos. Para Kenski (2010, p. 77):

É preciso primeiramente considerar e definir que tipo de educação se deseja desenvolver e que tipo de aluno se pretende formar [...] é necessário que, entre outras decisões, sejam identificadas entre as tecnologias disponíveis as que melhor se enquadrem às propostas educativas da unidade escolar.

A formação continuada do professor precisa levar em consideração o desafio de que as tecnologias comportam especificidades, trazem novas linguagens, a digitalização tem possibilitado a mobilidade e a convergência das mídias. É preciso que a formação continuada de professores que trata da integração das TICs na escola articule as linguagens e características das tecnologias digitais às especificidades e peculiaridades das ações didático-pedagógicas sob a mediação do professor. Cabe ao docene "trabalhar a aprendizagem nos meios eletrônicos, diminuindo a distância hoje vigente entre a modernidade dos instrumentos e o atraso didático" (DEMO, 2004, p. 85).

Por outro lado, é preciso deixar claro, em relação ao fetiche da tecnologia, que, por exemplo, o Facebook e o Orkut são ferramentas tecnológicas apropriadas pelos seres humanos, pelas comunidades sociais, transformandoas numa rede social, ou seja: o espaço ciber espacial interativo proporcionado pela tecnologia digital só se torna uma "rede social" pelo sentido e significado que o ser humano the confere (RECUERO, 2012).

\section{Práticas de INTEGRAÇÃo dAS TECNOLOGIAS NA ESCOLA}

A investigação se inscreve numa perspectiva qualitativa de pesquisa em Educação de cunho exploratório (LÜDKE; ANDRÉ, 1986; MONTEIRO, 1991). Objetivou-se investigar como tem ocorrido o uso dos recursos tecnológicos disponibilizados no Laboratório de Informática da escola pelo professor, a partir da proposta de formação continuada que procurou articular os conteúdos curriculares aos recursos tecnológicos disponíveis.

Em 2012, foram encaminhados questionários para 133 escolas municipais via e-mail utilizando a ferramenta disponível no Google Drive, com prazo de 15 dias para que fossem respondidos pelos professores que haviam participado das formações continuadas ofertadas pela mantenedora em 2011 e 2012. Vinte e sete escolas responderam o questionário, totalizando em torno de $20 \%$ do universo pesquisado. Dessas escolas, 35 professores responderam o questionário.

\section{A PARTICIPAÇÃO DOS PROFESSORES DOS CURSOS DE INTEGRAÇÃO DAS TICS}

Os professores pesquisados participaram dos cursos em que houve integração do setor de Tecnologias Digitais (Departamento de Tecnologia e Difusão Educacional) com o Departamento de Ensino Fundamental, ou seja, os cursos ${ }^{1}$ que trataram dos conteúdos dos diferentes componentes curriculares, como matemática, arte, língua portuguesa, educação física, entre outros, nos quais foram utilizados (integrados) os recursos tecnológicos para o desenvolvimento dos conteúdos (2011 e 2012).

Dos 35 professores que responderam o questionário, 28 atuam com os anos iniciais do Ensino Fundamental $\left(1^{\circ}\right.$ ao $5^{\circ}$ ano) e 8 com os anos finais $\left(6^{\circ}\right.$ ao $9^{\circ}$ ano). Um participou de mais de um curso e atua nos dois níveis de ensino.

Procurou-se relacionar os questionamentos realizados junto aos professores que participaram da pesquisa, levando em consideração que todos participaram da formação em serviço no período de 2011 e 2012. ${ }^{2}$

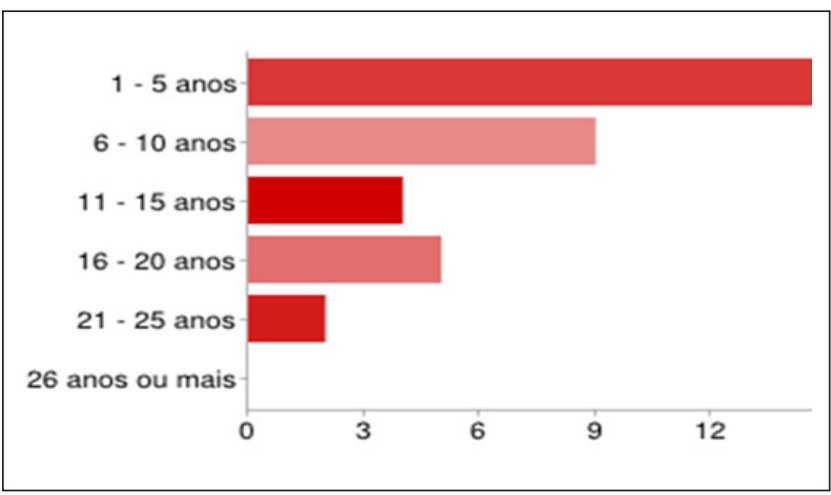

Gráfico 1 - Tempo de serviço na RME de Curitiba

De acordo como Gráfico 1, a maioria dos professores respondentes possui pouco tempo de atuação na Rede Municipal de Ensino - RME - de Curitiba, entre 1 a 5 anos, estão $43 \%$, o que representa 15 professores. Nove professores ficam compreendidos entre 6 e 10 anos de 
serviço, o que perfaz 26\% dos pesquisados. Quatro professores com 11 a 15 anos representam $11 \%$. Cinco professores se enquadram no período de 16 a 20 anos de atuação profissional e, por fim, dois professores têm mais de 21 anos de trabalho. Fica evidenciado que a maioria que retornou o instrumento de investigação tem pouco tempo de atividade docente na RME.

Quanto ao nível de ensino, $80 \%$, ou seja, 28 professores atuam da $1^{\mathrm{a}}$ a $5^{\mathrm{a}}$ série (Ensino Fundamental). Vinte e dois por cento, ou seja, sete professores pesquisados atuam de $6^{\mathrm{a}}$ à $9^{\mathrm{a}}$ série, conforme o Gráfico 2.

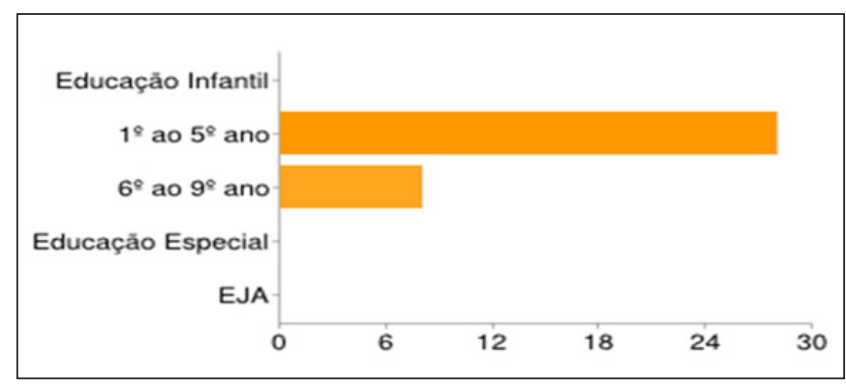

Gráfico 2 - Nível de ensino

\section{A UTILIZAÇÃo DE COMPUTADORES E RECURSOS TECNOLÓGICOS}

Em relação à utilização ou não do computador pelos professores em sua vida pessoal, procurou-se observar se essa "familiaridade" junto aos recursos tecnológicos perpassaria pelo empoderamento pessoal na apropriação e integração dessa tecnologia em atividades não pedagógicas anteriores à finalidade pedagógica. Verificou-se que apenas um dos 35 profissionais não utiliza o computador em suas atividades pessoais (Gráfico 3). Observa-se, portanto, certa familiaridade do docente com a tecnologia digital (computador), embora isso não seja necessariamente condição de apropriação teórica e metodológica do seu uso na escola.

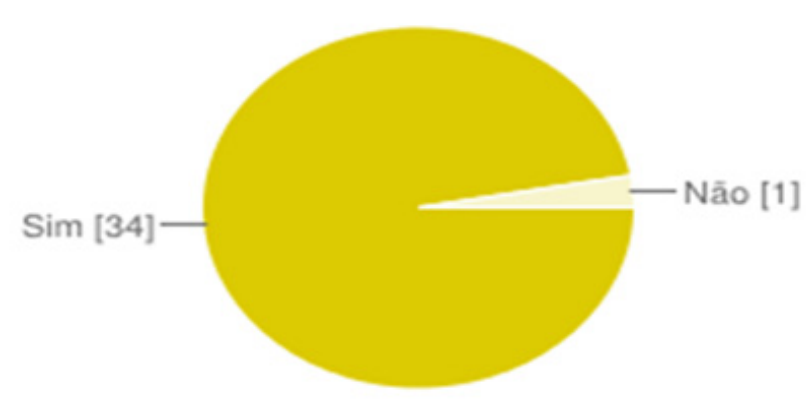

Gráfico 3 - Uso do computador na vida pessoal
Pode-se inferir na leitura do Gráfico 4 que há certa intimidade do professor com os recursos disponibilizados pelo computador, quando conectado ao ciberespaço. Para $100 \%$ dos professores pesquisados, o serviço mais utilizado é o correio eletrônico como meio de comunicação assíncrono (100\%).Trinta e três professores, ou seja, 94\% informaram que utilizam o computador na busca de informações por meio de pesquisas na internet. Oitenta por cento utilizam o computador para consulta a jornais e revistas. Vinte e cinco professores identificaram o uso das redes sociais e os sites para downloads. (Os respondentes puderam marcar mais de uma caixa de seleção; por isso, no Gráfico 4 a soma das porcentagens pode ultrapassar $100 \%$.)

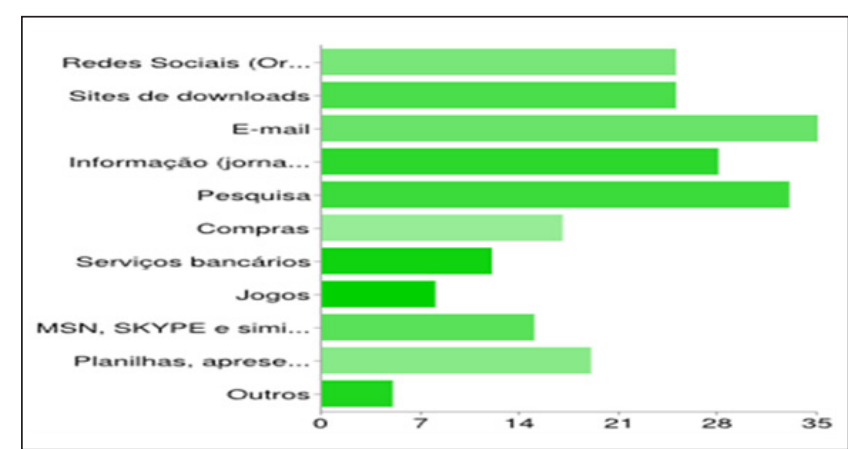

Gráfico 4 - Serviços e recursos disponíveis no computador utilizados pelos professores

\section{A UTILIZAÇÃo dOS RECURSOS PEDAGÓgICOS NAS PRÁTICAS DE ENSINO}

Quando questionados se utilizavam algum recurso tecnológico para o desenvolvimento das aulas, 32 professores, ou seja, 91\% disseram utilizar algum recurso no trato com os conteúdos e apenas três professores disseram não utilizar.

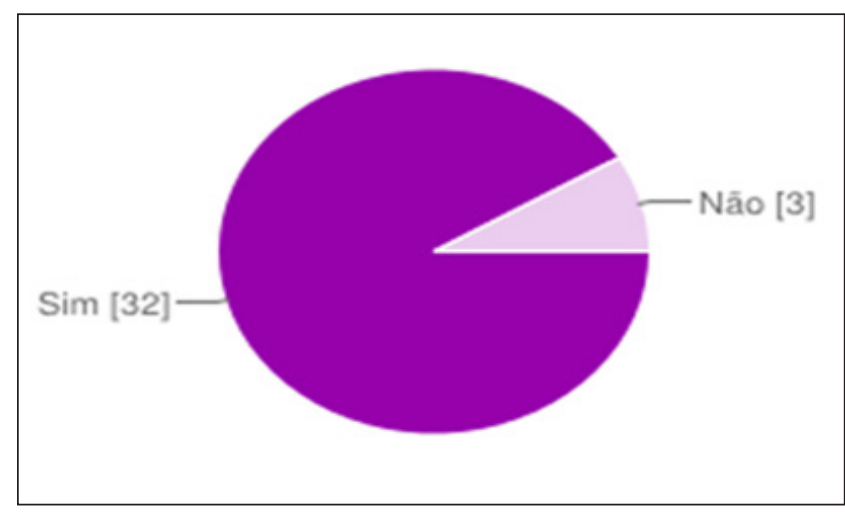

Gráfico 5 - Utilização de recurso tecnológico em sala de aula 
Dentre os recursos tecnológicos mais utilizados (não restringindo apenas ao computador), questionou-se aos professores (cursistas) quais eram os mais utilizados na sua prática pedagógica. Verificou-se que, dos recursos disponibilizados pela Secretaria Municipal de Educação (SME) às escolas, os vídeos com conteúdos dos diversos componentes curriculares são os mais utilizados pelos docentes, seguidos do rádio ou arquivos de áudio e das máquinas fotográficas, conforme o Gráfico 6 . (Os participantes puderam marcar mais de uma caixa de seleção; por isso, a soma das percentagens pode ultrapassar $100 \%$.)

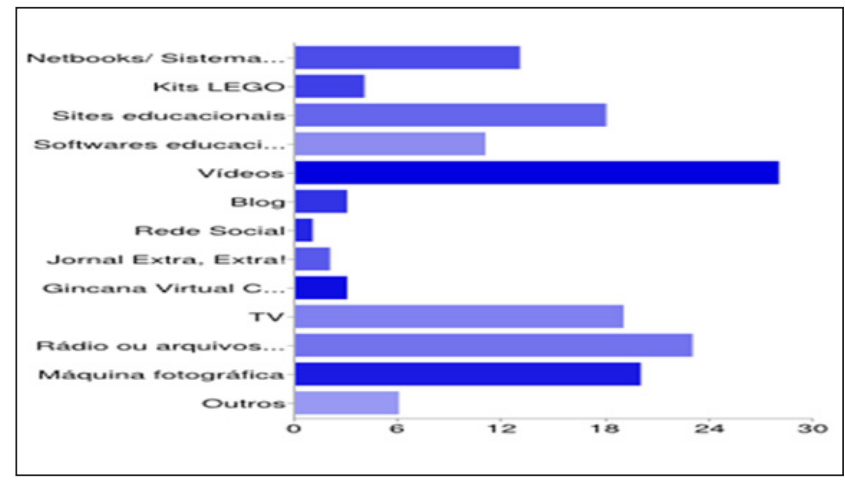

Gráfico 6 - Recursos tecnológicos mais utilizados em sala

Vinte e oito professores (80\%) utilizam os vídeos. Pode-se observar também que o uso do rádio ou arquivo em formato mp3 é utilizado por $66 \%$, o que equivale a 23 professores que responderam. Outros 20 disseram que utilizam a máquina fotográfica (57\%). Dezenove utilizam a televisão e dezoito apontaram para a pesquisa em sites educacionais.

Preliminarmente, os recursos tecnológicos são utilizados para uma complementação das atividades didático-pedagógicas. Há preocupação com os esclarecimentos dos conteúdos formalmente ministrados, incorporando, por exemplo: vídeos trabalhados com o auxílio do data show; uso da internet para pesquisas; uso da máquina fotográfica para registro e memória das aulas; criação de conteúdos multimídia; simulações e divulgação das produções. Há preocupação dos docentes em articular o uso dos recursos ao planejamento, fator esse representativo de uma tendência à integração inicial das tecnologias aos conteúdos, avançando do estágio de utilização meramente instrumental para um estágio com pequenas mudanças (MORAN, 2011).

Sobre o interesse e participação da formação continuada pelos professores para articulação dos recursos tecnológicos à sua prática pedagógica, 17 professores $(49 \%)$, realizaram de dois a três cursos que trataram do tema, seguidos de $37 \%$ que realizaram apenas um curso, o que corresponde a 13 professores do universo pesquisado. Vale ressaltar que dois professores realizaram de quatro a cinco cursos e três participaram de seis cursos ou mais (Gráfico 7).

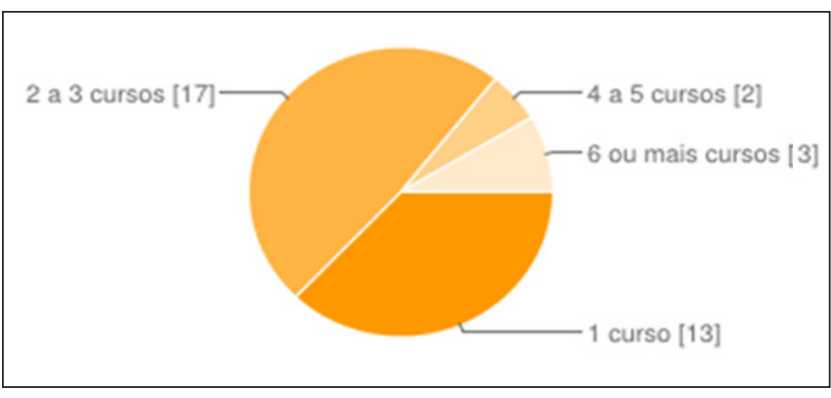

Gráfico 7 - Participação dos professores pesquisados em curso de formação

A maioria dos professores entrevistados disse que os cursos de capacitação sobre as TICs, lhes possibilitaram fundamentação teórica e prática que aperfeiçoam e integram à atividade docente. Um número menor mencionou dificuldade, sobretudo quando retornam à escola e precisam aplicar os conhecimentos que aprenderam nos cursos de capacitação, argumentando em relação à superficialidade com que o conteúdo foi abordado e à insuficiência do tempo destinado à interação com os recursos tecnológicos.

No sentido de aperfeiçoar a qualidade dos cursos, os professores sugeriram maior articulação entre a teoria ministrada na formação com as demandas das práticas pedagógicas relativas aos recursos tecnológicos disponíveis nas escolas. Manifestaram a necessidade de que os cursos de formação continuada indiquem, apontem e sugiram atividades práticas com uso das tecnologias. Alguns sugerem o aumento da carga horária e o aprofundamento do conteúdo ministrado e outros solicitaram maior oferta dos cursos em horários de permanência. ${ }^{3}$

Sobre as dificuldades no processo de integração dos recursos tecnológicos aos conteúdos planejados, os resultados apontaram, primeiramente, para a insuficiência no quantitativo de equipamentos disponíveis para toda a escola (professores e alunos), bem como para as dificuldades de ordem técnica, como defeitos e depreciação dos equipamentos.

As dificuldades de ordem pedagógica referemse a: não saber interagir com os softwares; falta de equipamentos em horários disponíveis; não conseguir articular os conhecimentos de apropriação e uso dos recursos tecnológicos com os conteúdos de sala de aula; escassez de softwares para o $6^{\circ}, 7^{\circ}, 8^{\circ}$ e $9^{\circ}$ anos em detrimento da variedade que existe para os anos iniciais; 
falta de hábito; quantidade de alunos em sala deaula; e tempo para estudo e elaboração dos materiais (PRETTO, 2013).

\section{Possibiliddades E LIMITES DO USO DOS RECURSOS TECNOLÓGICOS NAS PRÁTICAS DOCENTES}

A pesquisa revelou, em relação ao uso dos recursos tecnológicos nas atividades cotidianas, que hoje os professores, pelo menos os sujeitos da pesquisa, utilizam amigavelmente os recursos tecnológicos oferecidos pelos computadores em sua vida cotidiana. Dos que responderam os questionários, a quase totalidade relatou usar algum recurso tecnológico no desenvolvimento de suas aulas, o que aponta para um avanço, embora tímido, mas importante em termos educacionais, no processo de integração das tecnologias ao processo didáticopedagógico. Tímido no sentido de configurar um processo de integração que ainda carece de profundidade teórica e metodológica. Conforme Basso e Amaral (2006, p. 67), a questão hoje, sem dúvida, continua sendo o domínio do conteúdo por parte do professor para realizar o processo de ensinar de forma suficientemente didática para que o estudante compreenda e aprenda, o que implica a necessidade de

[...] competências e habilidades específicas de leitura de imagens, sinais eletrônicos, desde o rádio, a TV, os jornais impressos até a Internet, e-mails, chats, blogs, sites, pois estes se constituem em espaços de educação que estão assumindo o papel na formação de identidade e dão ao sujeito novos referenciais de leitura e escrita [...].

Sobre as vantagens na utilização dos recursos tecnológicos na aprendizagem de crianças e jovens estudantes, houve unanimidade. Todas as respostas corroboraram a ideia de que a utilização dos recursos tecnológicos torna as aulas mais dinâmicas e os alunos demonstram maior interesse nas atividades. Há, sobretudo, maior percepção da aprendizagem realizada.

Os recursos tecnológicos só podem ser utilizados com qualidade na escola se os equipamentos estiverem em condições de uso para que as atividades sejam desenvolvidas, e nesse sentido há um investimento a ser empreendido nas redes de ensino. O quantitativo de equipamentos disponíveis não é suficiente para uso de toda a comunidade escolar. A utilização está atrelada a uma grade horária previamente estabelecida. Além desse fator, evidenciou-se a necessidade de melhoria na manutenção dos equipamentos, tanto preventiva quanto corretiva.

Os resultados, ainda preliminares, da pesquisa empreendida demonstram, nas considerações dos pro- fessores pesquisados, a necessidade de formação em serviço que os instrumentalize para uma prática educativa na qual existam subsídios teóricos e práticos para a integração dos recursos tecnológicos à prática docente. Concorda-se com Dowbor $(2001$, p. 2) quando alude que não "[...] é apenas a técnica de ensino que muda, incorporando uma nova tecnologia. É a própria concepção do ensino que tem de repensar os seus caminhos".

\section{CONSIDERAÇõES FINAIS}

Em relação à concepção de formação continuada que promove o processo de integração do uso dos recursos tecnológicos, apresentou-se uma tentativa, ainda inicial, de integração das tecnologias aos conteúdos previstos no currículo da escola básica. Contudo, observou-se que a formação continuada oferecida ao professor é desenvolvida por dois diferentes tipos de formadores: os das áreas do conhecimento e os especialistas em tecnologia (educacional).

A concepção de formação continuada, portanto, apresenta-se de forma fragmentada, embora haja a indicação de um "diálogo" entre as áreas curriculares e as novas formas de utilização e leitura das possibilidades ofertadas pelas mídias digitais, o que sinaliza ainda um processo preliminar de agregação desses novos processos de conhecimento e formação tecnológicos à escolarização.

Há uma concepção que reflete a dicotomia entre os conteúdos curriculares e a tecnologia, entendida esta como "ferramenta", como "apoio", como instrumento técnico, complementar, instrumental. A formação docente, nessa perspectiva, carece, portanto, de uma concepção mais globalizante e complexa do fenômeno tecnologia em suas implicações científicas, políticas, culturais e educacionais.

A questão central que se depreende da pesquisa procura investigar o uso dos recursos tecnológicos a partir de uma formação continuada que intenta articular os conteúdos de área aos recursos tecnológicos (digitais), ou seja, uma articulação teórica e metodológica. É preciso que o conceito de integração dos recursos tecnológicos seja contextualizado; torna-se fundamental ao professor a compreensão de que o uso em si não possibilita efetiva integração e domínio sobre a tecnologia.

É preciso que o docente se aproprie dos fundamentos das linguagens veiculadas pelas mídias (SETTON, 2011) e que se manifestam de forma convergente no computador (tecnologia digital); é preciso, ainda, que o professor domine os aspectos culturais que se manifestam no/do uso das tecnologias digitais, compreendendo que as tecnologias podem franquear o "[...] acesso a múltiplas 
possibilidades de interação, mediação e expressão de sentidos, propiciados pelos recursos [...] dessas tecnologias"(ALONSO; VASCONCELLOS, 2012, p. 59).

A inquietação sobre uma concepção de formação continuada para professores do Ensino Fundamental propiciadora de elementos teóricos e metodológicos que fundamentem a integração crítica e propositiva dos recursos tecnológicos à prática educativa indica que é preciso avançar no sentido de tecer um diálogo mais efetivo entre o conteúdo, o conhecimento, a episteme e os meios e suas linguagens, processos veiculados pelas tecnologias digitais. Nessas diversas perspectivas, os professores tendem a aproximar-se também das apreensões e interesses dos alunos, já familiarizados com as mídias digitais, o que constitui requisito indispensável à docência na escola contemporânea.

\section{REFERÊNCIAS}

ASSMANN, Hugo (Org.). Redes digitais e metamorfose do aprender. Petrópolis: Vozes, 2005.

ANDRÉ, Marli E. D. A. de. O que é um estudo de caso qualitativo em educação? Revista da FAEEBA - Educação e Contemporaneidade, Salvador, v. 22, n. 40, p. 95-103, jul./ dez. 2013.

ALONSO, Kátia Morosov; VASCONCELOS, Maria Auxiliadora Marques. As tecnologias da informação e comunicação e a aprendizagem colaborativa no ensino fundamental. Revista Contrapontos - Eletrônica, v. 12, n. 1, p. 58-67, jan./abr. 2012.

BASSO, Ilda; AMARAL, Sérgio Ferreira do. Competências e habilidades no uso da linguagem audiovisual interativa sob enfoque educacional. ETD - Educação Temática Digital, Campinas, v. 8, n. 1, p. 51-72, dez. 2006.

CASTELLS, Manuel. A sociedade em rede. São Paulo: Paz e Terra, 1999. v. 1.

A galáxia da internet. Tradução de Maria Luiza X. de Albuquerque. Rio de Janeiro: Jorge Zahar, 2003.

CURITIBA. Diretrizes curriculares para a educação municipal de Curitiba: princípios para a educação em Curitiba. Curitiba, 2006. 2 v.

DEMO, Pedro. Professor do futuro e reconstrução do conhecimento. Petrópolis: Vozes, 2004.

DOWBVOR, Ladislau. Tecnologias do conhecimento: os desafios da educação. mar. 2001. Disponível em: <http://www. mhd.org/artigos/dowbor_tecnologias.html>. Acesso em: 01 jun. 2013.

GIL, Juana Maria Sancho. Em busca de respostas para as necessidades educacionais da sociedade atual: uma perspectiva multidisciplinar da tecnologia. Revista Linhas, Florianópolis, v. 14, n. 27, p. 9-44, jul./dez. 2013.

IANNI, Otávio. A sociedade global. 2. ed. Rio de Janeiro: Civilização Brasileira, 1993.

. Teorias da globalização. 4. ed. Rio de Janeiro: Civilização Brasileira, 1997.
KENSKI, Vani Moreira. Educação e tecnologias: o novo ritmo da informação. 7. ed. Campinas: Papirus, 2007.

Tecnologias e ensino presencial e a distância. 9. ed. Campinas: Papirus, 2010.

\section{3.}

Tecnologias e tempo docente. Campinas: Papirus,

LEMOS, André; LÉVY, Pierre. O futuro da internet: em direção a uma cibernética planetária. São Paulo: Paulus, 2010.

LÜDKE, Menga; ANDRÉ, Marli E. D. A. de. Pesquisa em educação: abordagens qualitativas. São Paulo: EPU, 1986. (Temas Básicos de Educação e Ensino).

LYOTARD, Jean Francois. O inumano. Considerações sobre o tempo. Lisboa: Estampa, 1988.

Moralités postmodernes. Paris: Galilée, 1993.

MARCELO, Carlos. Desenvolvimento profissional docente: passado e futuro. Sísifo - Revista de Ciências da Educação, Lisboa (Portugal), n. 8, p. 7-22, jan./abr. 2009.

MONTEIRO, Regina. A pesquisa qualitativa como opção metodológica. Revista Pro-Posições, Campinas, n. 5, p. 25-37, ago. 1991.

MORAES, Maria Cândida. Pensamento eco-sistêmico: educação, aprendizagem e cidadania no século XXI. Petrópolis: Vozes, 2004.

MORAN, José Manoel. Desafios da TV e do vídeo à escola. São Paulo, 2002. Disponível em: <http://www.eca.usp.br/ moran/desafio.htm>. Acesso em: 13 maio 2013.

A educação que desejamos: novos desafios e como chegar lá. 5. ed. Campinas: Papirus, 2011.

PRETTO, Nelson De Lucca. Diálogo com educadores. Espaço Pedagógico, Passo Fundo, v. 20, n. 2, p. 394-402, jul./dez. 2013.

RECUERO, Raquel. A conversação em rede: comunicação mediada pelo computador e redes sociais na internet. Porto Alegre: Sulina, 2012.

SANCHO, Juana Maria (Org.). Da fascinação ao desconcerto: a integração da informática na escola. Revista Pátio, Porto Alegre, ano 6, p. 27-31, jul./ago. 2002.

SANTAELLA, Lúcia. Da cultura das mídias à cibercultura: o advento do pós-humano. Revista FAMECOS, Porto Alegre, n. 22, p. 23-32, dez. 2003.

Pós humano - por quê? Revista da USP, São Paulo, n. 74, p. 126-137, jun./ago. 2007.

SCHWARTZ, Gilson. Tecnologias da informação e comunicação (TICs) e redes digitais. In: Indicadores de ciência, tecnologia e inovação em São Paulo - 2004. São Paulo: FAPESP, 2005. Disponível em: <http://www.fapesp.br/indicadores2004/ volume1/cap10_vol1.pdf>. Acesso em: 23 maio 2013.

SETTON, Maria da Graça. Mídia e educação. São Paulo: Contexto, 2011.

SILVA, Juremir Machado da. A sociedade midíocre. Porto Alegre: Sulina, 2012.

VALENTE, José Armando. Informática na educação: uma questão técnica ou pedagógica? Revista Pátio, Porto Alegre, ano 3, n. 9, p. 21-23, 1999. 


\section{NotAS}

1 A título de exemplificação descrevemos alguns títulos de cursos inferidos na pesquisa em questão: "Resolução de problemas matemáticos", "Ensino de História - relação e concepção de conteúdos metodológicos", "Introdução ao Ensino Religioso", "Geografia Urbana de Curitiba", "Caminhos possíveis - diferentes tipos de dança", "Gramática na escola", "Alfa-Lego", "Robótica como ferramenta de trabalhado para estudantes com altas habilidades", dentre outros.
2 Para as perguntas de múltipla escolha, disponibilizamos tabelas e gráficos gerados pelo software do Google Docs.

3 Permanência é o tempo disponibilizado pela mantenedora para formação continuada em serviço, planejamento das aulas, confecção de materiais, dentre outras atividades pedagógicas.

Artigo recebido em setembro 2013 Aprovado em dezembro 2013. 